\title{
The shaft resistance on axially loaded piles in clay
}

\author{
D. M. POTTS and J. P. MARTINS (1982). Géotechnique 32, No. 4, 369-386
}

\section{Dr D. J. Naylor, University College of Swansea}

The Authors' application of the critical state model to the problem of the resistance of axially loaded piles clarifies the mechanisms involved. It also raises some interesting questions, particularly relating to the importance of the initial stress assumption.

It has been assumed for the analyses that the initial principal stresses are horizontal and verti$\mathrm{cal}$, and that the horizontal principal stresses are both equal to $K$ times the vertical. While it is recognized in the Paper that this can only be expected to apply when there is minimal disturbance, such as with open-ended (nondisplacement) piles, the Authors do conclude that the peak friction angle $\left(\delta^{\prime}\right)$ is independent of the initial stress conditions. This raises the following questions relating both to the specific matter of the value of $\delta^{\prime}$ and more generally to the prediction of shaft resistance.

Does it follow that the shaft resistance as well as $\delta^{\prime}$ is insensitive to the initial stresses? Since the shaft resistance is proportional to the product of the radial effective stress $\left(\sigma^{\prime}\right)$ and $\tan \delta^{\prime}$, the small difference in $\sigma_{r}^{\prime} / c_{\mathrm{u} 0}$ between $K=0.7$ and 1.5 shown in Figs 13 and 14 would appear to suggest this.

What would be the effect of including an initial shear stress in the radial: vertical plane, as must surely exist in practice?

In carrying out the analyses with different $K$ values the specific volume was kept constant. Was there some reason for using this criterion? Had the vertical effective stress been kept constant then all the analyses would relate to a particular depth. Would this affect the conclusions?

No mention is made of the effect on the initial stresses of lateral movement of piles during their installation. Virtually all piles are driven-both displacement and non-displacement varieties. There will be both a Poisson's ratio effect whereby the pile expands radially and then contracts as the shock wave passes down it, and possibly also a lateral shake. This will induce some radial preconsolidation in the soil causing the radial initial stress (for subsequent loading) to be rather less than would otherwise be the case. The initial stress state might have $\sigma_{\theta}>$ $\sigma_{z}>\sigma_{r}$ rather than $\sigma_{\theta}=\sigma_{r}$ as has been assumed.
Could this explain why measured $\alpha$ values are sometimes less than expected theoretically? The Authors note near the end of the Paper that a large $\tau_{r z} / \sigma_{r}{ }^{\prime}$ reduction is required to produce observed $\alpha$ values, and they question the validity of cavity expansion theory. Perhaps the explanation lies in low initial $\sigma_{r}{ }^{\prime}$ values, which do not increase to the predicted values, rather than in a reduction in $\delta^{\prime}$.

Lastly, a comment on the presentation of the computed stress paths for the two models $A$ and $B$ : the writer found difficulty in comparing them. This difficulty could have been overcome by the use of the plane strain stress invariants $\sigma_{\mathrm{s}}{ }^{\prime}=$ $\frac{1}{2}\left(\sigma_{1}{ }^{\prime}+\sigma_{3}{ }^{\prime}\right)$ and $\sigma_{d}=\sigma_{1}-\sigma_{3}$ instead of $p^{\prime}$ and $J$ respectively for the axes for the model B stress paths (Figs 12 and 17). A unique line would then represent the critical state, exactly as in Figs 11 and 16 for model A. An even better comparison with model A could have been made if $J$ in Figs 11 and 13 had been replaced by $q=\sqrt{3} J$. This arises since $\sigma_{d}$ and $q$ are of similar magnitude becoming the same for the triaxial test condition: $\sigma_{1}>\sigma_{2}=\sigma_{3}$. Also $\sigma_{\mathrm{s}}^{\prime}$ and $p^{\prime}$ are of similar magnitude becoming the same for the hydrostatic stress condition $\sigma_{1}=\sigma_{2}=\sigma_{3}$. (The notation $\sigma_{\mathrm{s}}, \sigma_{\mathrm{d}}$ has been used to avoid the confusion in the literature over the names for these measures. The Cambridge school used $s$ and $t\left(\sigma_{\mathrm{s}}=\mathrm{s}, \sigma_{\mathrm{d}}=2 t\right)$. See for example Roscoe \& Burland (1968). In his book, Lambe \& Whitman (1969) unfortunately used $p$ and $q$ for the same measures.

\section{REFERENCES}

Lambe, T. W. \& Whitman, R. V. (1969). Soil mechanics. New York: Wiley.

Roscoe, K. H. \& Burland, J. B. (1978). On the generalised stress-strain behaviour of wet clays. In Engineering plasticity (eds J. Heyman and F. Leckie), pp 535-609. Cambridge: Cambridge University Press.

\section{Authors' reply}

In his discussion Dr Naylor has raised a number of questions. These are considered in the order posed.

The first relates to the behaviour of a pile installed without disturbance to either the stress 
field or the micro-fabric within the soil. According to the effective stress criterion adopted, the final unit shaft resistance is equal to the product of the tangent of the peak angle of shaft friction, $\delta^{\prime}$, and the corresponding radial effective stress acting on the pile. In the Paper, it was shown that the former is independent of initial stress conditions, whereas the latter is not necessarily so.

For ease of interpretation all the analyses performed started from the same specific volume (and hence the same undrained triaxial compressive strength). As may be seen in Figs 13 and 14 the initial radial stress is greater when $K=1.5$ than when $K=0.7$. During pile loading, however, the radial effective stress decreases by an amount which increases with the initial value of $K$ (see Fig. 15). The overall result is that the final radial stress, and consequently the peak unit shaft resistance, increases only slightly with $K$. However, it may be noted that the peak shaft resistance is proportional to the initial undrained shear strength, which is of course dependent on the initial stresses.

The effect of including an initial shear stress in the radial-vertical plane has not been investigated. The presence of such a shear stress will not affect the magnitude of $\delta^{\prime}$, whereas it may affect the variation in radial effective stress during loading, and also the early part of the loaddisplacement behaviour. The degree to which the initial shear stresses might influence the pile behaviour will, of course, depend both on their magnitude and direction. Little field data is available on this subject.

The same initial specific volume (and hence the same initial undrained shear strength, $c_{\mathrm{uo}}$ in triaxial compression) was employed in the analyses solely for ease of comparison and presentation of the results; all stresses may be normalized with respect to the initial undrained shear strength. If instead, the vertical effective stress had been kept constant then the initial undrained shear strength would have varied with $K$. However, the general trends observed, such as the variation of $\sigma_{r}{ }^{\prime} / \sigma_{r 0}{ }^{\prime}$ with $K$, would have been unchanged. Indeed, if normalized by the respective values of $c_{u 0}$, the stresses would have been essentially as presented in the Paper.

With regard to the behaviour of displacement piles, several analyses have been performed in which the relative magnitudes of the initial principal stresses $\sigma_{r}{ }^{\prime}, \sigma_{\theta}{ }^{\prime}$ and $\sigma_{z}{ }^{\prime}$ were varied, whilst the initial specific volume was kept constant (see
Martins, 1983). Although small differences in the loading behaviour was observed, the peak unit shaft resistances were almost constant. Martins \& Potts (1982) demonstrated that the peak unit shaft resistance is essentially controlled by the magnitude of the undrained shear strength beside the pile following installation and consolidation. Whereas it is essential to be able to predict this latter quantity, a more detailed analysis of the stresses is of secondary importance. Incidentally, this result provides some insight, in terms of effective stresses, into the rcason why total stress methods have worked as well as they have in predicting long-term pile capacities.

The Authors are in complete agreement with Dr Naylor in the belief that the radial effective stresses acting on displacement piles following installation and consolidation are often overestimated by theoretical analyses. In particular, the Authors believe that current predictions based on the cavity expansion theory are too high. However, the Authors also believe that the peak angles of shaft friction that may be mobilized beside displacement piles will often be lower than the intact values, as a result of fabric disturbance and particle re-orientation effects which occur during installation (see Martins, 1983). In fact, for long or compressible piles it is recommended that the value of $\delta^{\prime}$ associated with the ultimate pile capacity be obtained from direct shear interface tests (see Martins \& Potts, 1984).

Finally, with regard to the presentation of the stress paths, the Authors would like to make it quite clear that they did not experience any difficulty in making the necessary comparisons. However, Dr Naylor's suggestion of plotting the results in terms of plane strain invariants $\sigma_{\mathrm{s}}^{\prime}$ and $\sigma_{\mathrm{D}}$, might well have simplified the presentation. On the other hand, this could only have been achieved at the expense of introducing additional terms.

\section{REFERENCES}

Martins, J. P. (1983). Shaft resistance of axially loaded piles in clay. $\mathrm{PhD}$ thesis, University of London.

Martins, J. P. \& Potts, D. M. (1982). A numerical study of skin friction around driven piles 3 rd Int. Conf. Behaviour of Offshore Structures, Massachusetts Institute of Technology.

Martins, J. P. \& Potts, D. M. (1984). A lower bound to the shaft capacities of long piles driven in to clays. In preparation. 